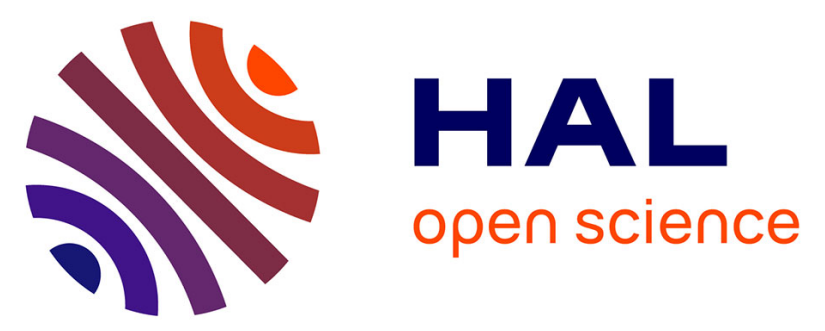

\title{
Potential impact of climate change on solar resource in Africa for photovoltaic energy: analyses from CORDEX-AFRICA climate experiments
}

\author{
Adeline Bichet, Benoit Hingray, Guillaume Evin, Arona Diedhiou, Cheikh \\ Mouhamed Fadel Kébé, Sandrine Anquetin
}

\section{To cite this version:}

Adeline Bichet, Benoit Hingray, Guillaume Evin, Arona Diedhiou, Cheikh Mouhamed Fadel Kébé, et al.. Potential impact of climate change on solar resource in Africa for photovoltaic energy: analyses from CORDEX-AFRICA climate experiments. Environmental Research Letters, inPress, 14 (12), pp.124039. 10.1088/1748-9326/ab500a . hal-02341149

\author{
HAL Id: hal-02341149 \\ https://hal.science/hal-02341149
}

Submitted on 26 Nov 2020

HAL is a multi-disciplinary open access archive for the deposit and dissemination of scientific research documents, whether they are published or not. The documents may come from teaching and research institutions in France or abroad, or from public or private research centers.
L'archive ouverte pluridisciplinaire HAL, est destinée au dépôt et à la diffusion de documents scientifiques de niveau recherche, publiés ou non, émanant des établissements d'enseignement et de recherche français ou étrangers, des laboratoires publics ou privés. 
LETTER • OPEN ACCESS

Potential impact of climate change on solar resource in Africa for photovoltaic energy: analyses from CORDEX-AFRICA climate experiments

To cite this article: Adeline Bichet et al 2019 Environ. Res. Lett. 14124039

View the article online for updates and enhancements. 


\title{
LETTER
}

CrossMark

OPEN ACCESS

RECEIVED

17 July 2019

REVISED

16 October 2019

ACCEPTED FOR PUBLICATION

22 October 2019

PUBLISHED

6 December 2019

Original content from this work may be used under

the terms of the Creative

Commons Attribution 3.0

licence.

Any further distribution of this work must maintain

attribution to the

author(s) and the title of

the work, journal citation

and DOI.

\section{Potential impact of climate change on solar resource in Africa for photovoltaic energy: analyses from CORDEX-AFRICA climate experiments}

\author{
Adeline Bichet $^{1}$ (D) , Benoit Hingray ${ }^{1}$ (D) , Guillaume Evin ${ }^{2}$ (D), Arona Diedhiou ${ }^{1,3}$ (D), \\ Cheikh Mouhamed Fadel Kebe ${ }^{4}$ and Sandrine Anquetin ${ }^{1}$ (1) \\ 1 University Grenoble Alpes, IGE UMR 5001, Grenoble, F-38000, France \\ 2 University Grenoble Alpes, Irstea, UR ETNA, Grenoble, France \\ 3 African Centre of Excellence on Climate Change, Biodiversity and Sustainable Agriculture (ACE CCBAD), University Félix Houphouët \\ Boigny, Abidjan, Côte d'Ivoire \\ 4 Centre for Incubation and Development of Innovative Companies (Innodev), University Cheikh Anta Diop, Dakar, Sénégal \\ E-mail: adeline.bichet@univ-grenoble-alpes.fr \\ Keywords: solar potential, solar radiation change, climate change, model projections, solar resource assessment, Bayesian ANOVA method \\ Supplementary material for this article is available online
}

\begin{abstract}
The development of renewable electricity in Africa could be massive in coming decades, as a response to the rapid rising electricity demand while complying with the Paris Agreements. This study shows that in the high-resolution climate experiments of CORDEX-AFRICA, the annual mean solar potential is expected to decrease on average by $4 \%$ over most of the continent by the end of the century, reaching up to $6 \%$ over the Horn of Africa, as a direct result of decrease in solar radiation and increase in air surface temperature. These projections are associated with large uncertainties, in particular over the Sahel and the elevated terrains of eastern Africa. While the expected decrease may affect the sizing of the numerous solar projects planned in Africa for the next decades, this study suggests that it does not endanger their viability. At last, this study indicates that the design of such projects also needs to account for the non-negligible uncertainties associated with the resource.
\end{abstract}

\section{Introduction}

Most of Africa's economy is growing at unprecedented speed, and the demand for electricity is expected to triple by 2030 [1]. To meet this rising demand while contributing to the objectives of the Paris Agreement, most African countries are expected to develop renewable electricity, typically solar, wind, and hydropower. Africa has an exceptional solar resource that can be harnessed for electricity generation [1]. Despite a strong influence of the nebulosity, solar resource remains generally high throughout the year over the entire continent [2]. Higher resource and higher temporal stability are found near the midlatitudes despite a strong monsoon-related seasonality $[3,4,5]$. Lower resource and lower temporal stability are found near the equator where a strong nebulosity is found during most part of the year (e.g. [2, 6]).
Whereas previous studies indicate a strong potential for solar energy over Africa under current conditions (e.g. [2]), very little is known about the future evolution of this potential. Yet, because solar power depends on incoming surface solar radiation (amount of sunlight reaching the Earth's surface) as well as on other atmospheric variables (e.g. temperature) affecting the photovoltaic (PV) panel efficiency [7, 8], it is expected to be sensitive to the long-term changes in climate and pollution levels. Note that the development of concentrated solar power (CSP) systems is also expected to increase in the coming decades. However, because PV projects are less limited and more numerous than CSP projects [9], we focus our study on PV systems, thus investigating the changes in global solar irradiance (GHI). A similar study could obviously be carried out for CSP systems, but this would involve investigating the changes in direct normal irradiance instead of GHI. 
Table 1. Summary of 17 simulations (GCM/RCM chains) taken from the CORDEX-AFRICA data. In this ensemble, five RCMs are used to downscale 10 GCMs. Each experiment comprises one historical and one scenario (RCP8.5) run, spanning the periods 1976-2005 and 2006-2099 respectively. The horizontal resolution of all simulations is $0.5^{\circ}$ in both latitude and longitude.

\begin{tabular}{|c|c|c|c|c|c|}
\hline $\mathrm{RCM} \backslash \mathrm{GCM}$ & HIRHAM5 (v2) & CCLM 4-8-17 (v1) & RACMO $22 \mathrm{~T}(\mathrm{v} 1)$ & RCA4 (v1) & REMO 2009 (v1) \\
\hline ICHEC-EC-EARTH & $\mathrm{x}$ & & $\mathrm{x}$ & $\mathrm{x}$ & $\mathrm{x}$ \\
\hline CNRM-CERFACS-CNRM-CM5 & & $\mathrm{x}$ & & $\mathrm{x}$ & \\
\hline MPI-M-MPI-ESM-LR & & $\mathrm{x}$ & & $\mathrm{x}$ & $\mathrm{x}$ \\
\hline NCC-NorESM1-M & & & & $\mathrm{x}$ & \\
\hline NOAA-GFDL-GFDL-ESM2M & & & & $\mathrm{x}$ & \\
\hline IPSL-IPSL-CM5A-MR & & & & $\mathrm{x}$ & \\
\hline MIROC-MIROC5 & & & & $\mathrm{x}$ & \\
\hline CSIRO-QCCCE-CSIRO-Mk3-6-0 & & & & $\mathrm{x}$ & \\
\hline CCCma-CanESM2 & & & & $\mathrm{x}$ & \\
\hline MOHC-HadGEM2-ES & & & $\mathrm{x}$ & $\mathrm{x}$ & \\
\hline
\end{tabular}

According to the projections of 39 global coupled atmosphere-ocean models (GCMs) under the RCP8.5 scenario taken from the CMIP5 project, the potential for solar energy is expected to decrease by mid-21st century, over a large part of the world including Africa [10]. The low resolution (temporal and spatial) of GCMs, however, limits a precise assessment at a regional scale. A better assessment requires using regional climate models (RCMs), which provide a higher spatial and temporal resolution, and thus a better representation of the topography, coastline, and small scale processes through the use of parametrization schemes [11-14]. Unfortunately, to date, with the noticeable exception of the study of [15] for the European region, no such study has been conducted at continental scales. This gap has obviously to be filled rapidly in regions where solar energy has been identified as a key contributor to a climate-friendly energy transition, such as Africa, where projections of solar resource are only available as part of global studies $[10,16,17]$ or at the country (e.g. [18, 19]) or regional level [20].

In this study, we use the outputs of CORDEXAFRICA [21-23], the most up-to-date ensemble of high-resolution regional climate projections for Africa, to investigate how the solar potential and its temporal variability are expected to change for this continent in the next decades. Solar radiation, air temperature and surface wind speed time series from each climate experiment are used to estimate the potential for solar power production and its expected time evolution for each grid cell of the domain and for nine regions with contrasted climates. The expected changes in this potential (mean and variability) are then assessed along with that of its weather drivers. We further characterize the uncertainty associated with expected changes and the proportion of this uncertainty due to different uncertainty sources, namely internal variability (IV) and model uncertainty due to GCMs and RCMs, respectively. Hence, as compared to previous regional studies (e.g. [20]), our study aims to evaluate the PV potential and its sensitivity to climate change over the whole African continent, in addition to characterize the total uncertainty associated with these projections and the different sources of this uncertainty.

Section 2 describes the data and the methodology. Section 3.1 investigates the future changes that are expected in the mean solar potential and its drivers, section 3.2 examines the future changes that are expected in the mean solar potential at a regional scale, and section 3.3 examines the future changes in the daily and annual temporal variability of solar energy potential. Section 4 discusses and concludes the study.

\section{Methodology and data}

\subsection{Datasets}

We use an ensemble of 17 regional climate simulations taken from the most up-to-date ensemble of highresolution RCM projections produced in the recent years for Africa: CORDEX-AFRICA [21-23]. In this ensemble, five RCMs are used to downscale 10 GCMs under the climate scenario RCP8.5 (table 1). The simulations span the period 1976-2099 at a daily time step, and cover Africa $\left(24.64^{\circ} \mathrm{W}-60.28^{\circ} \mathrm{E} ; 45.76^{\circ} \mathrm{S}-\right.$ $\left.42.24^{\circ} \mathrm{N}\right)$ with a spatial resolution of $0.5^{\circ}(\sim 50 \mathrm{~km})$ in latitude and longitude. For each simulation and each grid cell, daily time series of surface downwelling shortwave radiation (RSDS), surface air temperature (TAS), and 10 meters Wind speed (W10) are retrieved. As explained in the Methodology section, TAS and W10 are used to compute the solar potential, as they affect the temperature of the PV cells.

As an important prerequisite for this work, we evaluated the simulated RSDS for the period 1995-2005, by comparison with observed GHI taken from the high resolution satellite SARAH2 [24]. The data from SARAH2 is available since 1983, but because [25] found some horizontal stripes artifacts in the Meteosat SIS data over the period 1983-1994, we only use the data from 1995 onwards. In all four seasons, we find that the 17 climate experiments are able to capture the observed spatial distribution of the mean resource and its temporal variability, both being dominated by a significant latitudinal gradient (supplementary figure 1 is available online at 


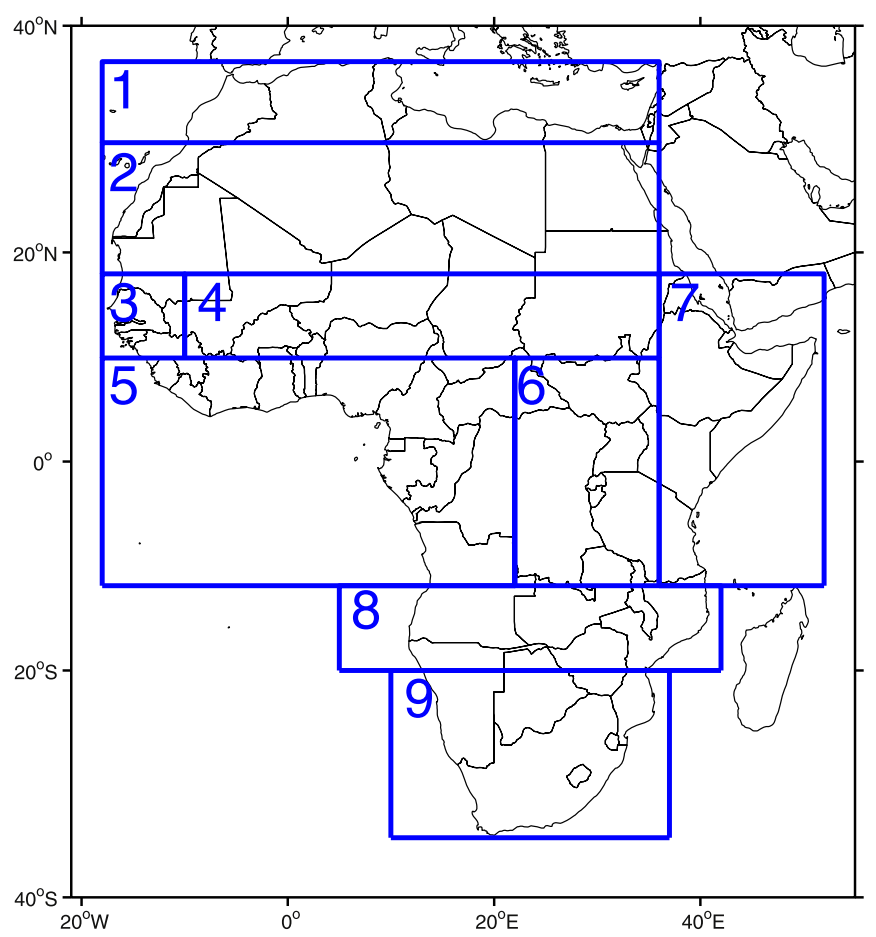

Figure 1. Regional analyses are performed on the nine climatic regions adapted from [30]: 1 . North Africa $\left(30^{\circ}-37^{\circ} \mathrm{N} ; 18^{\circ} \mathrm{W}-36^{\circ} \mathrm{E}\right)$, 2. Sahara $\left(18^{\circ}-30^{\circ} \mathrm{N} ; 18^{\circ} \mathrm{W}-36^{\circ} \mathrm{E}\right)$, 3. West Sahel $\left(10^{\circ}-18^{\circ} \mathrm{N} ; 18^{\circ}-10^{\circ} \mathrm{W}\right)$, 4. East Sahel $\left(10^{\circ}-18^{\circ} \mathrm{N} ; 10^{\circ} \mathrm{W}-36^{\circ} \mathrm{E}\right)$, 5. Guinea Coast $\left(12^{\circ} \mathrm{S}-10^{\circ} \mathrm{N} ; 18^{\circ} \mathrm{W}-22^{\circ} \mathrm{E}\right), 6$. East Africa $\left(12^{\circ} \mathrm{S}-10^{\circ} \mathrm{N} ; 22^{\circ}-36^{\circ} \mathrm{E}\right), 7$. Horn of Africa $\left(12^{\circ} \mathrm{S}-18^{\circ} \mathrm{N} ; 36^{\circ}-52^{\circ} \mathrm{E}\right)$, 8. Sub-South Africa $\left(20^{\circ}-12^{\circ} \mathrm{S} ; 5^{\circ}-42^{\circ} \mathrm{E}\right), 9$. South Africa $\left(35^{\circ}-20^{\circ} \mathrm{S} ; 10^{\circ}-36^{\circ} \mathrm{E}\right)$.

stacks.iop.org/ERL/14/124039/mmedia). Higher (lower) values of mean resource are found near the mid-latitudes (along the equator) in both datasets. Larger biases $(>10 \%)$ are found over the southern subtropics in December-January-February (DJF), the tropics in DJF (including West Sahel and Guinea Coast), and the Horn of Africa in March-April-May (MAM; supplementary figure 1). In all four seasons, both datasets show a daily variability $(20 \%)$ that is a factor 10 higher than the interannual variability (2\%), with the models slightly overestimating the observed interannual variability. Overall, the general agreement between the two datasets encourages the use of the CORDEX-AFRICA ensemble for investigating the projections of future solar potential in Africa.

\subsection{Methodology}

In this study, we focus on how the mean potential production of solar power (PVpot) for any given site is expected to evolve as a result of climate change. It must be noticed that this potential production is not directly related to the real production as the latter depends on the installed capacity. The installed capacity will likely grow rapidly in Africa owing to a lot of utility scale and offgrid projects of solar farms [1], and its evolution is a priori not linked to the climate evolution. The potential production PVpot characterizes the amount of solar energy that can be retrieved for a given site using PV cells. It depends on the local meteorological conditions and is thus linked to climate characteristics. For any given time $t$, the potential production (PVpot $(t))$ is defined as the ratio between (1) the production that would be obtained for that time as a result of the current weather conditions (wind, temperature and solar radiation) and (2) the production that would have been obtained under standard test weather conditions. PVpot $(t)$ is sometimes referred to as the 'capacity factor' of the PV cells for time $t$ [26]. It is dimensionless. In the present work, we compute $\operatorname{PVpot}(t)$ on a daily basis following [15, 27], as described in the 'Annex Methodology'. Changes in annual and seasonal mean PVpot values are then processed using the methodology described in the following.

The CORDEX-AFRICA multimodel ensemble used for this analysis (table 1) is associated with different sources of uncertainty, namely model uncertainty (uncertainty due to imperfections of climate models, i.e. GCMs or RCMs) and climate IV (variability in projections due to the chaotic and nonlinear nature of the climate system, which includes interannual variability here). To better understand the importance of these different uncertainty sources, they are partitioned and quantified using QUALYPSO [28], an advanced Bayesian ANOVA method based on data augmentation techniques and on the quasi-ergodicity assumption of climate outputs [29]. We quantify uncertainty sources for each grid cell of the African continent, for the projections of annual mean (aggregated from the daily time series) RSDS, W10, TAS, and PVpot. In addition, we split Africa into nine climatic regions, as described in figure 1, and apply the QUALYPSO method to the 

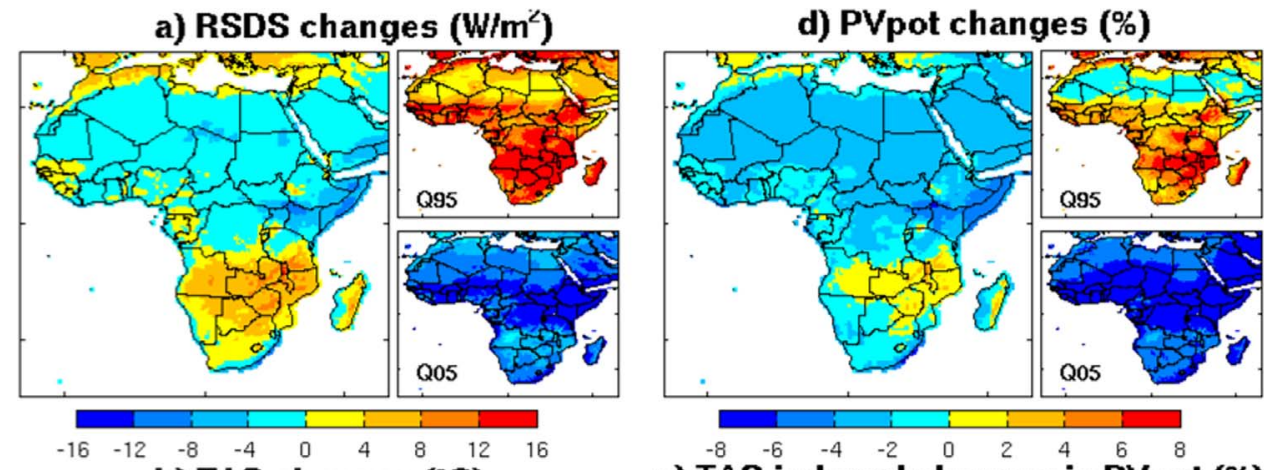

b) TAS changes $\left({ }^{\circ} \mathrm{C}\right)$

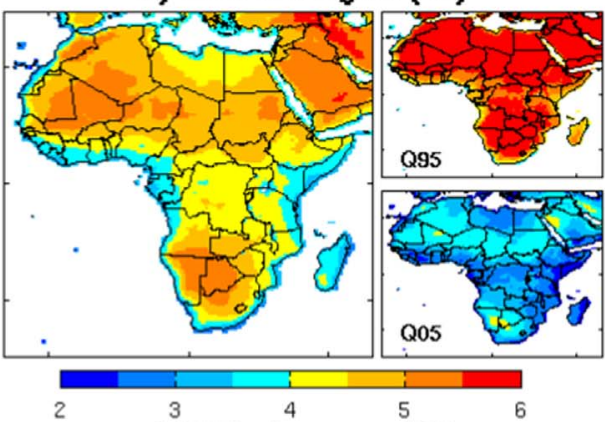

e) TAS-induced changes in PVpot (\%)
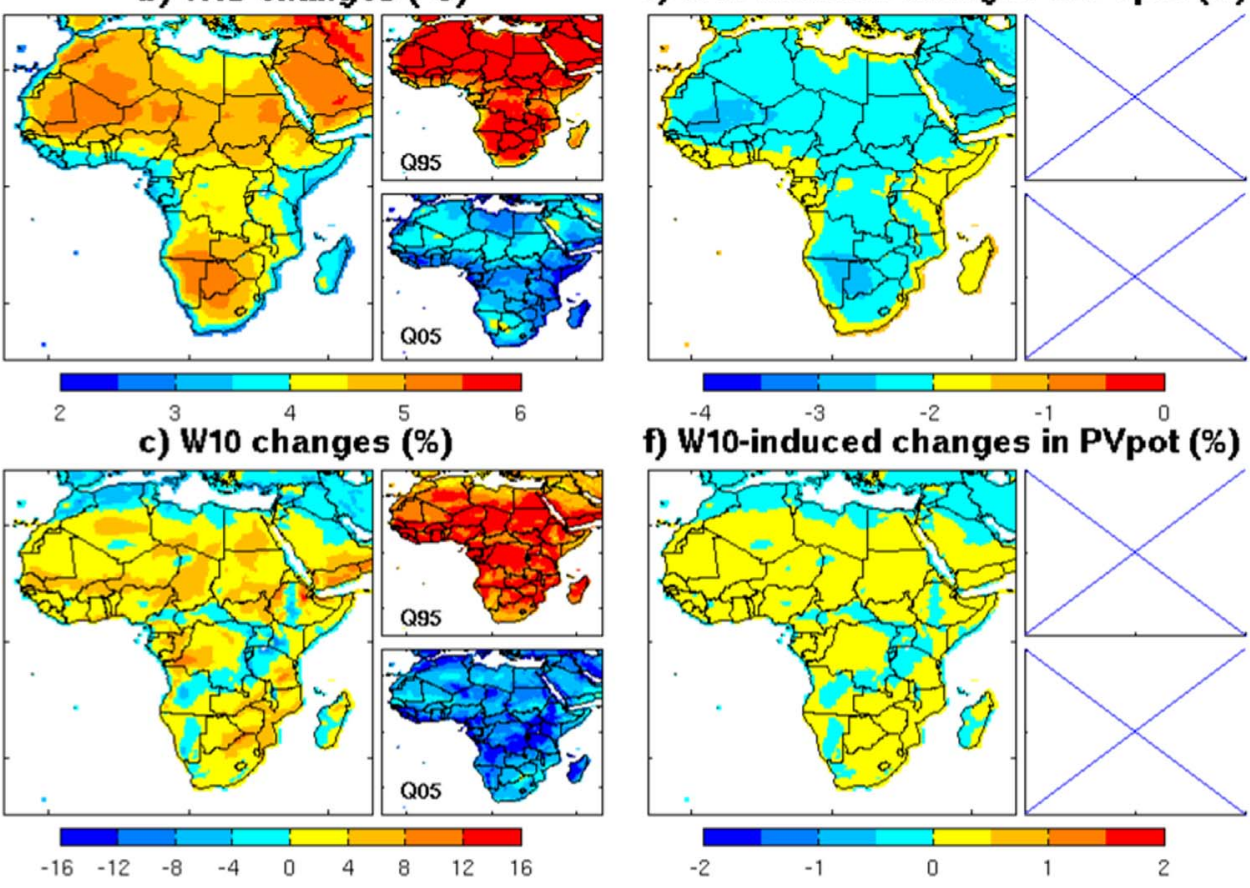

Figure 2. Ensemble mean climate change response $\mu$ for the end of the century (2070-2099), in (a) RSDS, (b) TAS, (c) W10, and (d) PVpot, in $\mathrm{W} \mathrm{m}^{-2},{ }^{\circ} \mathrm{C}, \%$, and \%, respectively, and in the PVpot changes that would be induced by the changes in either (e) TAS alone or (f) W10 alone, in \%. Also shown are the corresponding bounds (Q95 and Q05) of the $90 \%$ confidence interval. See the Methods section for details.

projections of annual mean values of the nine PVpot regional means. Finally, we compute the changes in the temporal variability of PVpot, as well as the changes in PVpot that are due to a change in either TAS (TAS-induced) or W10 (W10-induced), following [15]. Details of the computation are described in the 'Annex Methodology'.

\section{Results}

\subsection{Expected changes of mean PVpot and its drivers}

We comment here changes in mean PVpot expected by the end of the century (2070-2099). Figure 2 shows the ensemble mean change and the bounds of the $90 \%$ confidence interval of the projections for this variable (figure 2(d)) and its drivers (figures 2(a)-(c)). By the end of the century, except for some regions where it is expected to increase (up to $+2 \%$ in parts of southern Africa and along parts of the northern coast), PVpot is expected to decrease on average by $4 \%$ over the continent, reaching up to $6 \%$ over the Horn of Africa. These projections come with a large uncertainty and at the exception of the Sahara, the sign of change is actually uncertain (figure 2(d)). Thus, even though the mean change is relatively small $(-4 \%$ on average by the end of the century), large changes may actually occur in reality (from less than $-8 \%$ to more than $+8 \%$, figure $2(\mathrm{~d}))$. By the end of the century, the response to uncertainty ratio (R2U, figure 3) is only larger than 1 over the Sahara (region 2), East Sahel (region 4), and the Horn of Africa (region 7). It falls down to 0.6 over West Sahel and East Africa (regions 3 and 6), 0.5 over the Gulf of Guinea and South Africa (regions 5 and 9), and even 0.2 over Sub-South Africa (region 8).

Figure 4 shows the decomposition of the total uncertainty of PVpot. This total uncertainty is particularly large over the Sahel and the elevated terrains of eastern Africa (figure 4(a)), where a large part of total uncertainty results from RCM uncertainty 
a) RSDS changes $\left(\mathrm{W} / \mathrm{m}^{2}\right)$
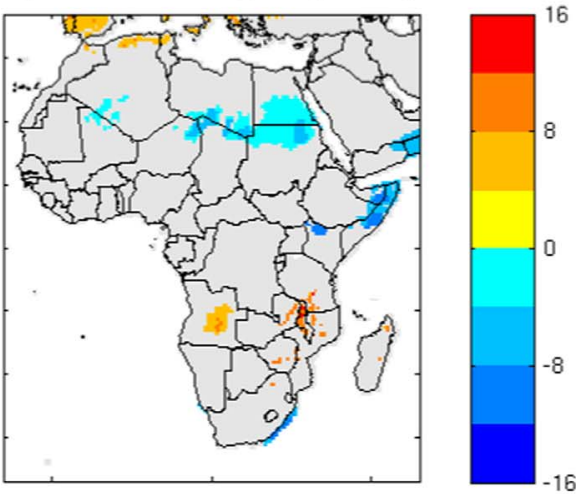

c) W10 changes (\%)

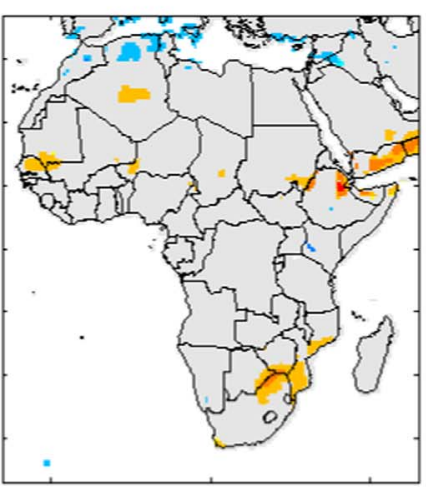

\section{b) TAS changes $\left({ }^{\circ} \mathrm{C}\right)$}

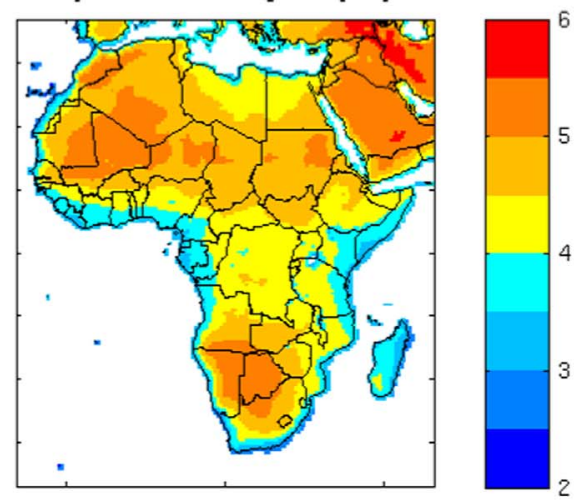

d) PVpot changes (\%)

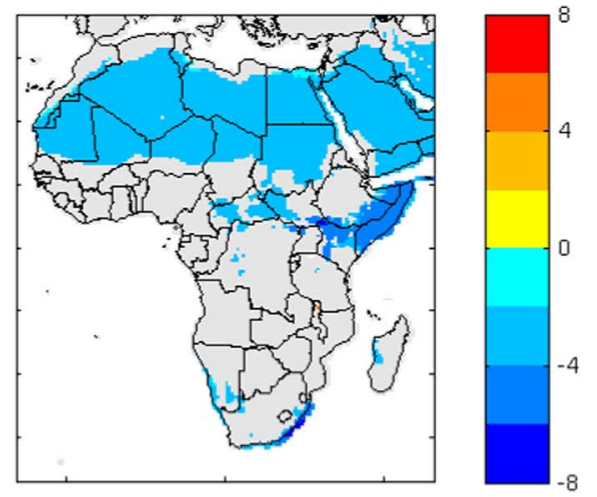

Figure 3. Ensemble mean climate change response $\mu$ for the end of the century (2070-2099), in (a) RSDS (W/m2), (b) TAS ( $\left.{ }^{\circ} \mathrm{C}\right),(\mathrm{c})$ $\mathrm{W} 10(\%)$, and (d) PVpot (\%), as seen in figure 1. The gray shaded area represents areas where $\mathrm{R} 2 \mathrm{U}<1$ ( $\mathrm{U}=$ total uncertainty). See the Methods section for details.

(figure 4(c)), as a result of large differences in the main effects obtained for RCM2 and RCM5 in Sahel and for RCM1 and RCM4 in the elevated terrains of eastern Africa (supplementary figure 2). Elsewhere, total uncertainty is smaller and results mostly from IV.

Hence, the projections of PVpot (figure 2(d)) mainly resemble the ones of RSDS (figure 2(a)). By the end of the century, RSDS is expected to decrease on average by $4 \mathrm{~W} \mathrm{~m}^{-2}$ over most the continent, reaching up to $12 \mathrm{~W} \mathrm{~m}^{-2}$ over the Horn of Africa (figure 2(a)). Exceptions where RSDS is expected to increase are southern Africa (up to $+6 \mathrm{~W} \mathrm{~m}^{-2}$ ) and parts of the northern and the western coasts. Uncertainty in RSDS projections is also logically similar to that of PVpot. It is also largely due to RCM uncertainty over the Sahel and the elevated terrains of eastern Africa, and IV elsewhere.

Expected changes in TAS and W10 can also modulate changes in PVpot. By the end of the century, TAS is expected to increase by $+5.5^{\circ} \mathrm{C}$ over western Sahel and Namibia/Botswana, $+5{ }^{\circ} \mathrm{C}$ over the midlatitudes, $+4.5^{\circ} \mathrm{C}$ over the equatorial region, and $+4{ }^{\circ} \mathrm{C}$ along the coasts, under the RCP8.5 scenario (figure 2(b)). The dispersion between climate projections is up to $3{ }^{\circ} \mathrm{C}$ by the end of the century; the total uncertainty mostly results from IV and GCM uncertainty (supplementary figure 3(b)). Overall, the significance of expected changes is high when compared to total uncertainties $(\mathrm{R} 2 \mathrm{U}>1$ whatever the region, figure $3(\mathrm{~b})$ ). Except along the northern coast and parts of central Africa where it decreases by up to $4 \%$ (figure 2(c)), W10 is expected to increase everywhere by up to $+8 \%$. For this variable, the dispersion between the projections is large, especially in equatorial regions (R2U $<1$ in most regions, figure $3(\mathrm{c})$ ). Total uncertainty mostly results from IV (up to $80 \%$ over the Sahel, Western Sahara, Horn of Africa, and along the southern coast) and GCM uncertainty (up to $80 \%$ over large parts of eastern Sahara (supplementary figure 3(c)).

Figures 2(e) and (f) show the changes in PVpot that would be induced by the end of the century solely by the changes in either TAS or W10, respectively. Change in TAS is expected to reduce PVpot over the entire continent, on average by $2.5 \%$ (figure $2(\mathrm{e})$ ). Conversely, changes in wind speed are not expected to really affect mean PVpot (induced changes are below $1 \%$, figure $2(\mathrm{f})$ ).

Hence, our results show that the PVpot spatial pattern of change (figure $2(\mathrm{~d})$ ) resembles the one of RSDS (figure 2(a)), albeit altered by the projected warming. Over parts of southern Africa and along parts of the 
a) PVpot total uncertainty (\%)

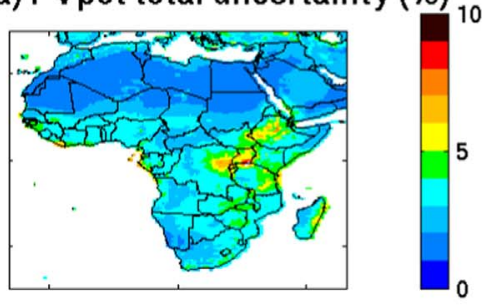

b) GCM contribution (\%)

c) RCM contribution (\%)
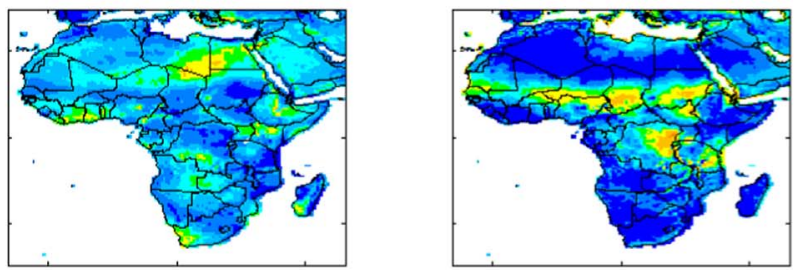

d) Internal variability contribution (\%)

e) Residual contribution (\%)
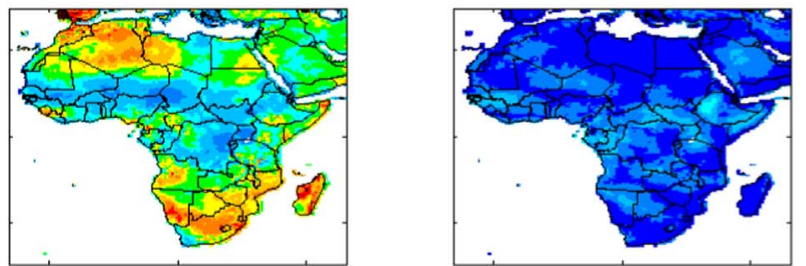

0

50

100

Figure 4. Decomposition of the total uncertainty of PVpot changes for the end of the century (2070-2099). Shown is the total uncertainty standard deviation (STD $=\sqrt{ } T$ ) of PVpot in $\%(a)$, and the contribution from each source of uncertainty (GCM (b), RCM (c), internal variability (d), and residual (e)), expressed in \% of contribution to total uncertainty. Here, $T$ corresponds to the total uncertainty variance, as described in the 'Annex Methodology'.

western and the northern coasts, the warming is indeed strong enough to offset the increase in RSDS and produce a decline in PVpot.

In addition figure 5 shows that the expected changes in PVpot can also depend on the season, especially for JJA and DJF. For example in June-July-August, PVpot is expected to increase on average by $+4 \%$ over the Sahel and along southwestern Africa by the end of the century, and decrease on average by $4 \%$ elsewhere, reaching up to $-8 \%$ along the coast of Guinea Coast. In September-October-November (SON), DJF, and MAM, PVpot is expected to increase by up to $+4 \%$ in parts of southern Africa and along parts of the northern coast, and decrease on average by $4 \%$ elsewhere, reaching up to $6 \%(8 \%)$ over the Horn of Africa in SON (DJF).

\subsection{Expected changes of mean PVpot at regional scales}

Figure 6 shows the PVpot changes over 1990-2099 in each region depicted in figure 1 . Shown are the ensemble mean climate change response $\mu$ (dark blue curve), the $90 \%$ confidence interval (black curves), and the individual contribution of each source of uncertainty (red: GCM uncertainty, green: RCM uncertainty, magenta: IV, black: model residuals).
Except in region 8 where it remains constant, PVpot steadily decreases throughout the 21 st century in all the regions. The mean projected changes exceed total uncertainty (R2U > 1) after 2024 in region 2, 2060 in region 4, 2085 in region 7, 2099 in region 1, and never elsewhere. Accounting for this uncertainty, we find that the probability for PVpot to decrease by more than $5 \%$ (which corresponds to a significant change for electricity production) by 2050 (2099) is of $0 \%$ $(0.4 \%)$ in region $1,0 \%(5.9 \%)$ in region $2,3.2 \%$ $(14.7 \%)$ in region $3,1.2 \%(13.2 \%)$ in region $4,4.1 \%$ $(17.5 \%)$ in region $5,2.2 \%(10.6 \%)$ in region $6,3.3 \%$ $(18.7 \%)$ in region $7,0.8 \%(2.2 \%)$ in region 8 , and $0.9 \%$ $(5.2 \%)$ in region 9 . Thus, even though the probability for a meaningful decrease is relatively small by 2050, it becomes likely $(10 \%-20 \%)$ by the end of the century over most of the continent (Sahel, Guinea Coast, and eastern Africa (regions 3, 4, 5, 6 and 7, respectively)). In all regions, the confidence interval of the projected changes increases throughout the century as a result of increasing model uncertainty. Results can vary from one region to the other: in the northern regions, the confidence interval remains relatively small and the three sources of uncertainty equally contribute after about 2050; in the tropical regions and the Sahel however, the contribution from RCM uncertainty 

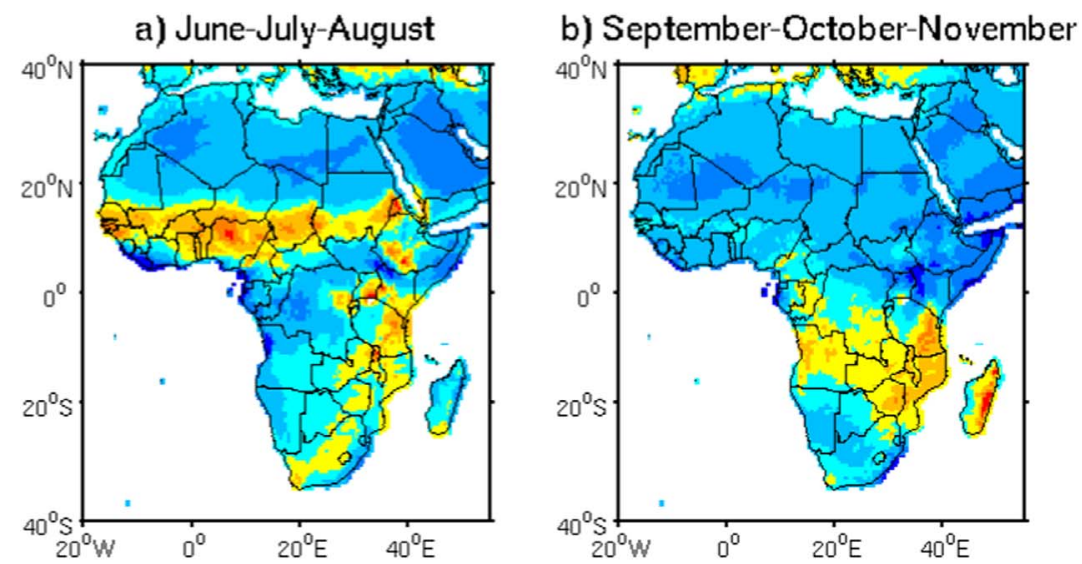

c) December-January-February

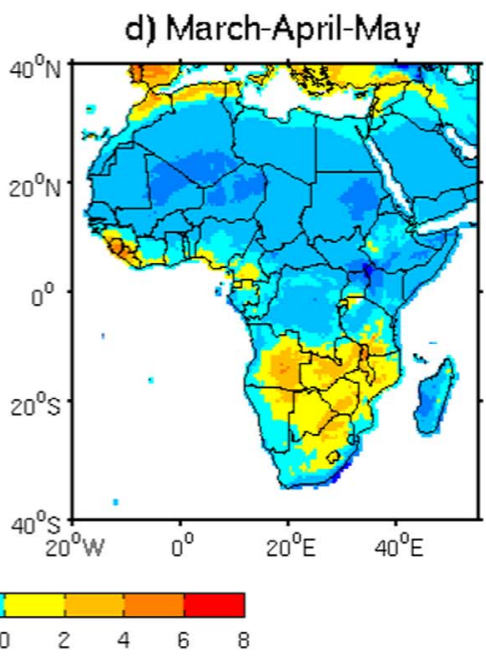

Figure 5. Ensemble mean climate change response $\mu$ for seasonal mean PVpot for the end of the century (2070-2099; \%), as averaged over (a) June-July-August (JJA), (b) September-October-November (SON), (c) December-January-February (DJF), and (d) MarchApril-May (MAM).

strongly increases throughout the century and prevails after about 2050; at last in the southern regions, the contribution from IV remains very high throughout the century, and in South Africa, the contribution from GCM uncertainty is higher than the one from RCM after 2050.

Furthermore, we show (supplementary figure 4) that the confidence interval can be very different in the seasonal means as compared to the annual means, and from one season to another. For example, the confidence interval over the Sahel is very large in JJA but very small in DJF. Conversely over southern Africa, the confidence interval is very large in DJF and MAM, but much smaller in JJA and SON. In the annual means and the seasonal means, the confidence interval generally increases as a result of RCM uncertainty.

\subsection{Expected changes in the temporal variability of PVpot}

Figures 7(a) and (b) show the mean changes in PVpot annual (a) and daily (b) variability for each region by the end of the century (red dot), in addition to the results obtained for each simulation chain respectively (blue dots). Annual and daily variability are not expected to change a lot on average, whatever the region. Annual variability is expected to change by a maximum of $1 \%$ (as compared to the value of PVpot over the reference period) depending on the simulation, generally increasing in regions 1 (North Africa), and decreasing in region 3, 8, and 9 (West Sahel and southern Africa, figure $7(\mathrm{a})$ ). The daily variability is expected to change by a maximum of $1.5 \%$ (as compared to the value obtained for PVpot over the reference period) depending on the simulation, generally increasing in regions 5 and 6 (Guinea Coast and East Africa), and decreasing in regions 1, 8, and 9 (North Africa and southern Africa, figure 7(b)). The expected change is rather low on average for the whole ensemble, but may be rather large depending on the models. For a number of regions, even the sign of change is not certain. For instance, the daily variability may either increase or conversely decrease depending on the simulation chain. Additional analyses (supplementary figures 5) show that interannual variability is 


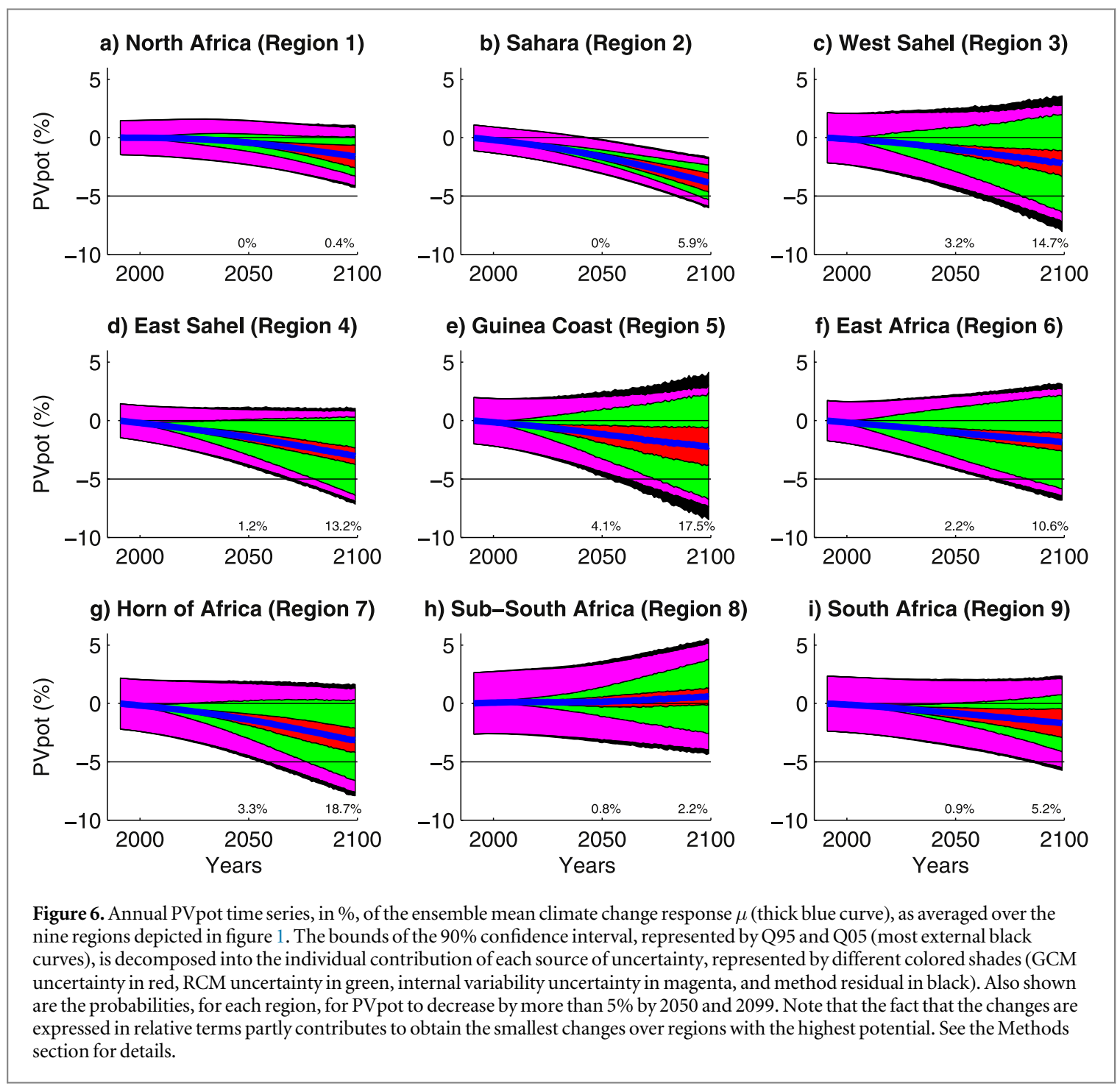

expected to stay relatively stable in all four seasons, with a large dispersion across models, except for DJF where it clearly decreases in almost all the models in region 1 (North Africa) and 2 (Sahara), on average by $1 \%$ (as compared to the value of PVpot over the reference period). Daily variability is also expected to stay relatively stable in all four seasons, with a large dispersion across models, especially over the Sahel (region 3 and 4) in JJA and SON. In addition, daily variability is expected to clearly increase in region 7 (Sub-South Africa) in SON and in region 5 (Guinea Coast) in DJF, and clearly decrease in regions 8 and 9 (southern Africa) in JJA and SON, and in region 1 in SON and MAM.

\section{Discussion and conclusion}

In agreement with previous studies (e.g. [10, 20]), we find that except for a few regions (northern coast and $10^{\circ} \mathrm{S}$ ), the annual mean solar potential in Africa is expected to decrease over the 21 st century (on average by $4 \%$ ), in particular over the Horn of Africa (up to $6 \%$ ). In addition, the solar potential is expected to increase on average by $+4 \%$ over the Sahel in JJA (rainy season over the Sahel), and decrease by more than $8 \%$ over the Horn of Africa in DJF. As in [20], we find that the expected reduction in solar potential is a direct result of decreasing solar radiation (except for southern Africa where solar radiation increases) and increasing temperature (decreases PVpot on average by $2.5 \%$ points; we recall here that this estimation is relatively approximative, as PVpot is computed from daily means (see Annex Methodology)). The warming-induced reduction, also seen in Europe [15] and West Africa [20], calls for future efforts to reduce the dependency of the PV cells performance on the ambient temperature [31]. As for Europe [15], our results project little changes in the temporal stability (daily, annual, and decadal) of the solar potential in all seasons.

Large uncertainties are associated with our projections, except over the Sahara where uncertainty is very small (only resulting from IV; figures 2-4, and 6). Elsewhere, even the sign of change is not sure, depending on the simulation chain considered. The same applies for possible changes in variability (figure 7). This 


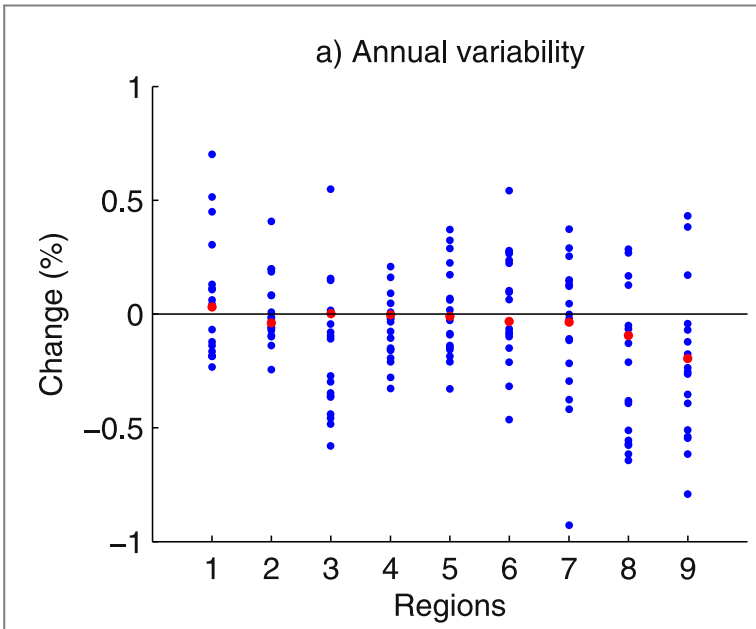

b) Daily variability

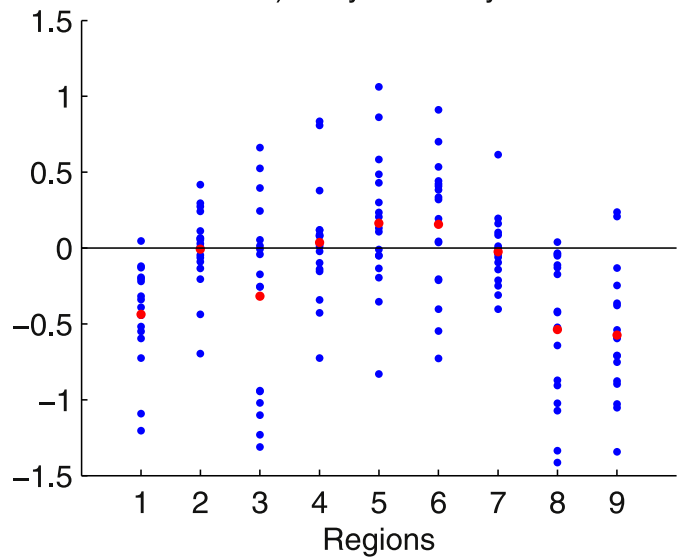

Figure 7. Projected changes of the PVpot (a) annual variability and (b) daily variability, in \%, as averaged over the nine regions depicted in figure 1 . Shown are the anomalies ((2070-2099)-(1976-2005)) of the annual and daily variability, expressed in \% as compared to the reference mean value of PVpot, computed from the 17 raw simulations (blue dots) and the corresponding ensemble mean (red dots). See the Methods section for details.

implies that despite a small change in the ensemble mean (mean resource and variability of the resource), important changes may actually occur in reality. In particular, we find that the probability for the annual mean solar potential to decrease below $5 \%$ is quasi null by 2050 , but reaches $10 \%-20 \%$ by the end of the century over most of the continent (Sahara, Sahel, Guinea Coast, and eastern Africa; figure 6). Over the Sahel, this probability is still high in JJA (10.5\% in 2050 and $18 \%$ by the end of the century) despite the projected strong increase in mean solar potential $(+4 \%$ on average by the end of the century; supplementary figure 4). Over the Horn of Africa, this probability is very high in DJF (26\% in 2050 and $51.3 \%$ by the end of the century) due to the strong decrease projected in the DJF solar potential (more than 8\%; supplementary figure $4)$. The stability of the resource (mean and variability) is thus to be put in perspective compared to this relatively large uncertainty. Although the significant uncertainty associated to projections has not the capacity to endanger the development and viability of solar projects in this region [32-35], it should be accounted for during the design of solar projects.

This uncertainty mainly results from RCM uncertainty over most of the continent. A large part of total uncertainty is also due to climate IV over southern Africa, the Guinea Coast and parts of the northern coast. In these regions, the irreducible IV will lead to rather large, unpredictable, variations of the resource. Elsewhere, uncertainty can be reduced with the improvements of RCMs. In particular, we suggest that the different parametrizations used in each RCM, and more specifically the ones for cloud cover and convection (supplementary figure 6), play an important role explaining this large RCM dispersion (e.g. [36, 37]). An in-depth investigation is required to fully address this issue, which is currently ongoing. Note also that [11] shows that the projections of solar radiation is different in the multimodel mean GCMs than it is in the multimodel mean RCMs because of the different behavior of the cloud cover in global and regional models, which further highlights the important role of cloud cover simulation. At last, it is important to recall that an additional source of uncertainty, not accounted for in QUALYPSO, results from the quality of the projections (mean and variability), that varies greatly from a region to another (supplementary figure 1).

A more critical limitation is likely related to the impacts of aerosols, abundant in Africa. Aerosols, natural (e.g. Saharan dust) and anthropogenic (e.g. pollution), can significantly affect the potential for solar production (e.g. [38]). First, they fully modulate RSDS via their direct impacts on the incoming solar radiation and their indirect impacts on cloud cover. In addition, their deposition on PV arrays is expected to decrease the efficiency of PV cells. Thus, a modification of aerosols concentrations as a result of land use changes, modification in dust events intensity and frequency (and especially Saharan dusts), or pollution, could have a critical effect on the potential for solar production. For instance, the expected changes in surface wind speed seen in figure 2(c) can affect the solar potential via their impacts on the synoptic circulation and the displacement of dust from the source (e.g. Sahara) to the different regions of Africa. Unfortunately, the RCMs used in CORDEX-AFRICA poorly represent these different interactions of the aerosols with the climate. In addition, the climate scenarios used in CORDEX-AFRICA (e.g. RCP8.5) have been shown to strongly underestimate the present and future anthropogenic emissions of aerosols in Africa [39]. Depending on the future policy scenarios for anthropogenic emissions of aerosols, solar potential over Africa could thus vary by up to $7 \%$ in 2030 [38]. According to the authors, this impact is related to the global effect of the aerosols on the large 
scale circulation and associated cloud cover patterns, rather than to their local effects on the atmospheric properties. A deep investigation of the skill of current models to simulate relevant aerosols dynamics and concentration and in turn of the effects of aerosols on solar resource is definitely to be carried out in future works.

Finally, as in [10], our projections result solely from the future changes imposed in the forcings under the RCP8.5 scenario. Although the identification of such forcings is beyond the scope of this study, we suggest that the projected warming results at least partly from the imposed increase in greenhouse gases (e.g. [40]), while the projections of RSDS result at least partly from the imposed changes in aerosols, through their impacts on the local atmospheric optical properties and/or cloud cover patterns (e.g. [38]). In fact, the resemblance between our projected RSDS pattern of change and the projected cloud cover pattern of change from the fifth assessment report (cloud cover is projected to increase (decrease) by about $+5 \%(5 \%)$ over eastern (southern) Africa; [40]) points towards a strong role of the nebulosity in explaining the projections of RSDS. As previously mention, the important role of cloud cover is also suggested by [11], and our study further supports this point.

\section{Acknowledgments}

The research leading to this publication received funding from the French public research institution IRD, and was supported by the French National program LEFE (Les Enveloppes Fluides et l'Environnement). We acknowledge the usage of the CORDEXAFRICA dataset from the World Climate Research Program's Working Group on Regional Climate (http://cordex.org/data-access/esgf/), and the usage of the SARAH2 dataset (https://wui.cmsaf.eu/safira/ action/viewDoiDetails?acronym=SARAH_V002).

This work is a contribution to CORDEX-AFRICA initiative. The research leading to this publication is co-funded by the NERC/DFID 'Future Climate for Africa' program under the AMMA-2050 project, Grant No. NE/M019969/1 and by IRD (Institut de Recherche pour le Développement; France). We also thank the staff at the IGE computation center (Patrick Juen and Wajdi Nechba) for their technical support, as well as Nicolas Plain for his role in accessing the SARAH2 data and his insights into the dataset.

\section{Annex Methodology}

\section{A.1. Computation of the power generation potential PVpot}

Following $[15,27]$, the potential production of solar power for a given time $t$ can be computed as follows:

$$
\operatorname{PVpot}(t)=P_{R}(t) \operatorname{RSDS}(t) / \operatorname{RSDS}_{\mathrm{STC}},
$$

where $\operatorname{RSDS}(t)$ is surface downwelling shortwave radiation for $t$, the production for the standard test conditions is $\mathrm{RSDS}_{\mathrm{STC}}=1000 \mathrm{~W} \mathrm{~m}{ }^{-2}$, and $P_{R}$ is the performance ratio of the PV cells, expressed as

$$
P_{R(t)}=1+\gamma\left[T_{\text {cell }}(t)-T_{\mathrm{STC}}\right]
$$

where $T_{\text {cell }}$ is the PV cell temperature, $T_{\text {STC }}=25^{\circ} \mathrm{C}$, and $\gamma=-0.005^{\circ} \mathrm{C}^{-1}$, considering the typical response of monocrystalline silicon solar panels. $T_{\text {cell }}$ is expressed as a linear function of TAS, RSDS and W10:

$T_{\text {cell }}(t)=c_{1}+c_{2} \operatorname{TAS}(t)+c_{3} \operatorname{RSDS}(t)+c_{4} \mathrm{~W} 10(t)$,

with $c_{1}=4.3^{\circ} \mathrm{C}, c_{2}=0.943, c_{3}=0.028^{\circ} \mathrm{C} \mathrm{m}^{2} \mathrm{~W}^{-1}$, and $c_{4}=-1.528{ }^{\circ} \mathrm{Cs} \mathrm{m}^{-1}$ [41]. Hence, if ambient conditions correspond to the standard conditions, $\operatorname{PV} \operatorname{pot}(t)$ equals 1 and PV power production reaches the rated value. If $T_{\text {cell }}>25^{\circ} \mathrm{C}$ and/or RSDS $<$ $1000 \mathrm{~W} \mathrm{~m}^{-2}$, then $\operatorname{PVpot}(t)<1$ and the PV production is lower than the rated value. Because CORDEXAFRICA is only available at the daily time step, we apply the instantaneous $\operatorname{PV} \operatorname{pot}(t)$ equations described above to daily means. Although this may trigger a slight difference due to the covariability between temperature and radiation (low temperature at night, large temperature during daytime), additional analyses (not shown) show that in the West African stations tested, simulations with high resolution data show no significant differences with daily mean simulations. We expect those results to be rather similar for the whole continent.

We consider the impact of climate change on the annual and seasonal mean potential production, as well as on its day-to-day and year-to-year variability. At last, we compute the changes in PVpot resulting from changes in either TAS (TAS-induced) or W10 (W10-induced) as detailed in [15] and described further down. At this point, note that our study does not account for other parameters affecting the outdoor performance of PV modules efficiency such as deposition of dust on the PV panels, nor the tilt of the PV panels, the solar spectrum distribution and the air mass effect on it $[42,43]$.

\section{A.2. Estimation of the different sources of uncertainty using QUALYPSO}

Conversely to typical ANOVA approaches used for such analysis, QUALYPSO [28] allows for a robust partition and for an unbiased estimation of all uncertainty components in multimember multimodel ensembles of projections, even in the case of single run ensembles (i.e. when only one experiment is available for some or all simulation chains; which is the case here as only one run is available for each GCM) and even when ensembles are incomplete (i.e. when not all GCM/RCM combinations are available which is also the case here; only 17 GCM/RCM combinations are available out of the $50(=10 \times 5)$ possible GCM/ 
RCM combinations, see table 1). Using QUALYPSO, we can estimate the mean climate change response of the considered variable, the total uncertainty of the projections and the contribution of the different uncertainty components to it. More specifically, the different steps of QUALYPSO are as follows.

1. For each climate chain (each GCM/RCM combination), extraction of the climate response of the chain for the considered variable achieved by fitting a trend model.

2. For each climate chain, computation of the change variables (i.e. absolute or relative differences) between a future and a reference period (centered here on 1990).

3. Using the climate change responses of all available GCM/RCM chains, estimation of the mean climate change response of the ensemble of chains.

4. Decomposition of the climate change response using an analysis of variance (ANOVA) model. The deviations of each GCM and each RCM from the mean climate change response of the ensemble are estimated using data augmentation and Bayesian methods.

5. The dispersion (variance) between the main effects obtained for the different GCMs (resp. RCMs) gives an estimate of the model uncertainty due to GCMs (resp. RCMs). We refer to this dispersion as GCM (resp. RCM) uncertainty in the text.

6. The IV is estimated by the variance of the deviations from the climate change response of the simulation chains.

For further details on the method, the reader is referred to [28]. QUALYPSO estimates can be produced for each prediction lead time. Here, we mainly present results obtained for changes between 2070-2099 and 1976-2005. Note that for W10 and PVpot, QUALYPSO is applied on the change variable, as we argue that for W10 and PVpot, the simulated changes are more reliable than the absolute values. Hence, for W10 and PVpot, the projected changes in mean W10, mean PVpot, are expressed in relative terms $(\%)$.

In our work, we give the ensemble mean and the $90 \%$ confidence interval of the projections derived from QUALYPSO. Under the assumption that change variables for each year $t$ are normally distributed, the bounds of this interval are obtained from quantiles 95 (Q95) and 05 (Q05) as follows:

$$
\begin{aligned}
& \mathrm{Q} 95(t)=\mu(t)+1.96 \sqrt{T(t)}, \\
& \quad \times \text { and Q05 }(t)=\mu(t)-1.96 \sqrt{T(t)},
\end{aligned}
$$

where $\mu(t)$ is the ensemble mean climate change response, and $T(t)$ is the total uncertainty variance. We additionally compute the response-to-uncertainty ratio (R2U), as the ratio between the ensemble mean climate change response $\mu(t)$ and the total uncertainty standard deviation $(\operatorname{STD}(t)=\sqrt{T(t)})$. Thus, R2U is a measure of the significance of changes, i.e. when $\mathrm{R} 2 \mathrm{U}>1$, the magnitude of the signal exceeds standard deviation of the ensemble.

\section{A.3. Computation of TAS-induced and W10- induced PVpot changes}

For each of the $17 \mathrm{GCM} / \mathrm{RCM}$ chains, we compute the changes in PVpot due to a change in either TAS (TASinduced) or W10 (W10-induced) as follows. Following [15], the changes in $\operatorname{PVpot}(t)$ that result from a change in TAS can be expressed as

$$
\begin{aligned}
& \Delta \text { TAS_induced_PVpot }(t) \\
& =\alpha_{3} \operatorname{RSDS}(t) . \Delta \operatorname{TAS}(t),
\end{aligned}
$$

where $\triangle \mathrm{TAS}(t)$ is the change in TAS (=TAS anomalies computed from the TAS climate response of the chain), $\operatorname{RSDS}(t)$ is the absolute value of RSDS taken from the RSDS climate response of the chain, and $\alpha_{3}=-4.715 \times 10^{-6} \mathrm{~W} \mathrm{~m}^{-2}$. Then, we express PVpot in relative term as follows:

$$
\begin{aligned}
& \Delta \text { TAS_induced_PVpot_rel }(t) \\
& \quad=\left(\alpha_{3} \operatorname{RSDS}(t) . \Delta \mathrm{TAS}\right) / \mathrm{PV} \operatorname{pot}_{\mathrm{ref}},
\end{aligned}
$$

where $\triangle$ TAS_induced_PVpot_rel $(t)$ is the $\Delta$ TAS_induced_PVpot $(t)$ relative to the reference period, and PVpot $_{\text {ref }}$ is the absolute value of PVpot for the reference period, taken from the PVpot climate response of the chain. Using $\operatorname{RSDS}(t)=$ $\operatorname{PVpot}(t) \cdot \operatorname{RSDS}_{\mathrm{STC}} / P_{R}(\mathrm{t})$ from equation (1) we obtain

$$
\begin{aligned}
& \Delta \text { TAS_induced_PVpot_rel }(t) \\
& =\left(\alpha_{3} \cdot \operatorname{PV} \operatorname{pot}(t) . \operatorname{RSDS}_{\mathrm{STC}} / P_{R}\right. \\
& \quad \times(t)) \cdot \Delta \mathrm{TAS} / \mathrm{PVpot}_{\mathrm{ref}},
\end{aligned}
$$

where $P_{R}(t)$ is computed from the raw simulations according to equation (2), and $\operatorname{PVpot}(t)$ and $\operatorname{PVpot}_{\text {ref }}$ are taken from the PVpot climate response. The same procedure is applied to W10 using (adaptation from equation (5)) of [15]:

$$
\begin{array}{r}
\Delta \text { W10_induced_PVpot }(t) \\
=\alpha_{4} \operatorname{RSDS}(t) . \Delta \mathrm{W} 10,
\end{array}
$$

where $\alpha_{4}=7.64 \times 10^{-6} \mathrm{~W} \mathrm{~m}^{-2} \mathrm{~m} \mathrm{~s}^{-1}$. Note that the uncertainty range is not presented for TAS-induced and W10-induced because they cannot be computed due to the expression of equations (5)-(8).

\section{A.4. Analyzing the temporal variability}

We analyze temporal variability at the daily and annual time scales. We compute both variables from 30 year periods. For interannual variability, we first detrend the time series of the annual values obtained for each GCM/RCM chain using the climate response of the chain (to avoid capturing long-term changes rather than those occurring at the scales of interest). For daily variability, the daily time series of each chain is also 
detrended, and the annual cycle is removed (to avoid the masking effect of this cycle; practically, for each calendar day, the interannual mean value for that calendar day is removed). The daily and yearly variability are computed as the normalized standard deviation of these preprocessed time series, and expressed in \%. The normalization consists in dividing the standard deviation by the climatology of the reference period (1976-2005). The described procedure is applied to each of the 17 raw time series of PVpot before computing the corresponding ensemble mean. Note that since variability is expressed in percentages, the projected changes in variability are given in percentage points.

\section{Data availability statements}

The data that support the findings of this study are openly available at https://doi.org/10.5676/EUM_ SAF_CM/SARAH/V002 ([44]; SARAH2); and https://doi.org/10.1594/WDCC/CXAF44CLCL ([45]; CORDEX-AFRICA CLM). The remaining experiments from CORDEX-AFRICA (SMHI 2017, DMI 2017, GERICS 2017, and KNMI 2017) data will soon be openly available at DOI: https://cera-www. dkrz.de/WDCC/ui/cerasearch/q? page $=0 \&$ query $=$ cordex + AFR-44\&rows $=15$.

\section{ORCID iDs}

Adeline Bichet (1D https://orcid.org/0000-00031409-1620

Benoit Hingray (i) https://orcid.org/0000-00016991-0975

Guillaume Evin (1D https://orcid.org/0000-0003-

3456-9441

Arona Diedhiou (10) https:// orcid.org/0000-00033841-1027

Sandrine Anquetin (10) https://orcid.org/0000-00015127-1650

\section{References}

[1] IRENA 2015 Africa 2030: Roadmap for a Renewable Energy Future (Abu Dhabi: International Renewable Energy Agency)

[2] Plain N, Hingray B and Mathy S 2019 Accounting for low solar resource days to size $100 \%$ solar microgrids power systems in Africa Renewable Energy 131 448-58

[3] Redelsperger J-L, Thorncroft CD, Diedhiou A, Lebel T, Parker D J and Polcher J 2006 African monsoon multidisciplinary analysis: an international research project and field campaign Bull. Am. Meteorol. Soc. 87 1739-46

[4] Sterl S, Liersch S, Koch H, van Lipzig N P M and Thiery W 2018 A new approach for assessing synergies of solar and wind power: implications for West Africa Environ. Res. Lett. 13 094009

[5] Lothon M, Saïd F, Lohou F and Campistron B 2008 Observation of the diurnal cycle in the low troposphere of West Africa Mon. Weather Rev. 136 3477-500

[6] Harrison E, Minnis P, Barkstrom B, Ramanathan V, Cess R and Gibson R 1990 Seasonal variation of cloud radiative forcing derived from the Earth radiation budget experiment J. Geophys. Res.: Atmos. 95 18687-703

[7] Dajuma A, Yahaya S, Touré E, Diedhiou A, Adamou R, Konaré A, Sido M and Golba M 2016 Sensitivity of solar photovoltaic panel efficiency to weather and dust over West Africa: comparative experimental study between Niamey (Niger) and Abidjan (Côte d'Ivoire) Comput. Water Energy, Environ. Eng. 5 123-47

[8] Radziemska E 2003 The effect of temperature on the power drop in crystalline silicon solar cells Renew. Energy 28 1-12

[9] Labordena M, Patt A, Bazilian M, Howells M and Lilliestam J 2017 Impact of political and economic barriers for concentrating solar power in Sub-Saharan Africa Energy Policy $10252-72$

[10] Wild M, Folini D, Henschel F, Fischer N and Müller B 2015 Projections of long-term changes in solar radiation based on CMIP5 climate models and their influence on energy yields of photovoltaic systems Sol. Energy 116 12-24

[11] Bartók B, Wild M, Folini D, Lüthi D, Kotlarski S, Schär C, Vautard R, Jerez S and Imecs Z 2017 Projected changes in surface solar radiation in CMIP5 global climate models and in EURO-CORDEX regional climate models for Europe Clim. Dyn. 49 2665-83

[12] Giorgi F, Marinucci M R and Visconti G 1990 Use of a limited area model nested in a general circulation model for regional climate simulation over Europe J. Geophys. Res. 95 413-8

[13] Paeth H and Mannig B 2013 On the added value of regional climate modeling in climate change assessment Clim. Dyn. 41 1057-66

[14] Torma C S, Giorgi F and Coppola E 2015 Added value of regional climate modeling over areas characterized by complex terrain-precipitation over the Alps J. Geophys. Res.: Atmos. $1203957-72$

[15] Jerez S et al 2015 The impact of climate change on photovoltaic power generation in Europe Nat. Commun. 610014

[16] Crook J A, Jones L A, Forster P M and Crook R 2011 Climate change impacts on future photovoltaic and concentrated solar power energy output Energy Environ. Sci. 93101-9

[17] Zou L, Wang L, Li J, Lu Y, Gong W and Niu Y 2019 Global surface solar radiation and photovoltaic power from coupled model intercomparison project phase 5 climate models J. Clean. Prod. 224 304-24

[18] Lawin A E, Niyongendako M and Manirakiza C 2019 Solar irradiance and temperature variability and projected trends analysis in burundi Climate 783

[19] Ohunakin O S, Adaramola M S, Oyewola O M, Matthew O J and Fagbenle R O 2015 The effect of climate change on solar radiation in Nigeria Sol. Energy 116 272-86

[20] Bazyomo S D Y B, A Lawin E, Coulibaly O and Ouedraogo A 2016 Forecasted changes in West Africa photovoltaic energy output by 2045 Climate 453

[21] Giorgi F, Jones C and Asrar G R 2009 Addressing climate information needs at the regional level: the CORDEX framework WMO Bull. 58 175-83

[22] Hewitson B, Lennard C, Nikulin G and Jones C 2012 CORDEX-Africa: a unique opportunity for science and capacity building CLIVAR Exchanges 17 6-7

[23] Jones C G, Giorgi F and Asrar G 2011 The coordinated regional downscaling experiment: CORDEX; an international downscaling link to CMIP5 CLIVAR Exchanges 56 34-40

[24] Pfeifroth U, Kothe S, Mûller R, Trentmann J, Hollmann R, Fuchs P and Werscheck M 2017 Surface Radiation Data SetHeliosat (SARAH)_Edition 2 (Satellite Application Facility on Climate Monitoring) (https://doi.org/10.5676/ EUM_SAF_CM/SARAH/V002)

[25] Journée M and Bertrand C 2011 Quality control of solar radiation data within the RMIB solar measurements network Sol. Energy 85 72-86

[26] IRENA 2018 Renewable Power Generation Coasts in 2017 (Abu Dhabi: International Renewable Energy Agency)

[27] Mavromatakis F et al 2010 Modeling the photovoltaic potential of a site Renew. Energy 35 1387-90 
[28] Evin G, Hingray B, Blanchet J, Eckert N, Morin S and Verfaillie D 2019 Partitioning uncertainty components of an incomplete ensemble of climate projections using data augmentation J. Clim. 32 2423-40

[29] Hingray B and Saïd M 2014 Partitioning internal variability and model uncertainty components in a multimember multimodel ensemble of climate projections J. Clim. 27 6779-98

[30] Giorgi F and Francisco R 2000 Uncertainties in regional climate change prediction: a regional analysis of ensemble simulations with the HADCM2 coupled AOGCM Clim. Dyn. 16 169-82

[31] Patt A, Pfenninger S and Lilliestam J 2013 Vulnerability of solar energy infrastructure and output to climate change Clim. Change 121 93-102

[32] IRENA 2016 Solar PV in Africa: Costs and Markets (Abu Dhabi: International Renewable Energy Agency)

[33] Ouedraogo N S 2017 Modeling sustainable long-term electricity supply-demand in Africa Appl. Energy 190 1047-67

[34] Ouedraogo N S 2017 Africa energy future : alternative scenarios and their implications for sustainable development strategies Energy Policy 106 457-71

[35] Trotter P A, Maconachie R and McManus M C 2018 Solar energy's potential to mitigate political risks: the case of an optimised Africa-wide network Energy Policy 117 108-26

[36] Lara-Fanego V, Ruiz-Arias J A, Pozo-Vazquez D, Santos-Alamillos F J and Tovar-Pescador J 2012 Evaluation of the WRF model solar irradiance forecasts in Andalusia (southern Spain) Sol. Energy 86 2200-17

[37] Prein A F et al 2015 A review on regional convectionpermitting climate modelling: demonstrations, prospects, and challenges Rev. Geophys. 53 232-361

[38] Gaetani M, Huld T, Vignati E, Monforti-Ferrario F, Dosio A and Raes F 2014 The near future availability of photovoltaic energy in Europe and Africa in climate-aerosol modeling experiments Renew. Sustain. Energy Rev. 38 706-16

[39] Liousse C, Assamoi E, Criqui P, Granier C and Rosset R 2014 Explosive growth in African combustion emissions from 2005 to 2030 Environ. Res. Lett. 9035003

[40] Collins M et al 2013 Long-Term Climate Change: Projections, Commitments and Irreversibility. In: Climate Change 2013: The Physical Science Basis. Contribution of Working Group I to the Fifth Assessment Report of the Intergovernmental Panel on Climate Change ed T F Stocker et al (Cambridge: Cambridge University Press)

[41] Chenni R, Makhlouf M, Kerbache T and Bouzid A 2007 A detailed modeling method for photovoltaic cells Energy 32 1724-30

[42] De Soto W, Klein S A and Beckman W A 2006 Improvement and validation of a model for photovoltaic array performance Sol. Energy $8078-88$

[43] Minemoto T, Nagae S and Takakura H 2007 Impact of spectrum irradiance distribution and temperature on the outdoor performance of amorphous Si photovoltaic modules Sol. Energy Mater. Sol. Cells 91 919-23

[44] Müller R, Pfeifroth U, Träger-Chatterjee C, Cremer R, Trentmann J and Hollmann R 2015 Surface Solar Radiation Data Set_Heliosat (SARAH)_Edition 1 (Satellite Application Facility on Climate Monitoring) (https://doi.org/10.5676/ EUM_SAF_CM/SARAH/V001)

[45] Panitz H-J, Schubert-Frisius M and Dosio A 2015 CORDEX simulations (evaluation, historical, rcp85, and rcp45) on a ca. $50 \mathrm{~km}$ grid over Africa based on CCLM4-8-17 forced by MPIESM-LR, EC-EARTH, CNRM-CM5 and HadGEM2-ES World Data Center for Climate (WDCC) at DKRZ (https: / / doi.org/10.1594/WDCC/CXAF44CLCL) 